\title{
Karadeniz’e Kıyısı Bulunan Ülkelerin Karadeniz’deki Balıkçıık Yetki Alanları ve Balıkçılık Faaliyetleri
}

\section{İsmet BALIK}

Ordu Üniversitesi, Fatsa Deniz Bilimleri Fakültesi, Ordu, Türkiye

Sorumlu Yazar: ibalik@hotmail.com

Geliş 13 Ağustos 2018; Kabul 09 Ekim 2018; Basım 01 Haziran 2019.

Alıntılama: Balık, İ. (2019). Karadeniz'e kıyısı bulunan ülkelerin Karadeniz'deki balıkçılık yetki alanları ve balıkçılık faaliyetleri. Acta Aquatica Turcica, 15(2), 117-125. https://doi.org/10.22392/actaquatr.577155

\section{Özet}

Bu çalışmada, Karadeniz'e kıyısı olan Türkiye, Gürcistan, Rusya Federasyonu, Ukrayna, Romanya ve Bulgaristan'ın balıkçılık sahalarının ve av güçlerinin büyüklüğü tespit edilmiş, 1950 yılından itibaren kıyıdaş ülkelerin bu denizden avladıkları su ürünlerinin miktarları incelenmiştir. Av ve av gücü verileri "www.seaaroundus.org" ve FAO balıkçılık istatistiklerinden alınmıştır. Bunun yanı sıra ülkelerin resmi istatistikleri ve yapılan bilimsel araştırmaların sonuçlarından da yararlanılmıştır. Kıyıdaş ülkelerin Karadeniz'den elde ettikleri toplam avın 1950'li yıllarda 400-500 bin ton yıl ${ }^{-1}$ arasında değiştiği, 1980'li yıllarda ise 1.3 milyon ton yıl ${ }^{-1}$ 'a kadar yükseldiği tespit edilmiştir. Ancak, 1980'li yılların sonunda hızlı bir azalma gösteren Karadeniz'den elde edilen balık üretimi 1990'lı yılların başlarında 500 bin ton y11 ${ }^{-1}$ ' 1 altına kadar düşmüştür. 1990'lı yılların başından günümüze kadar olan yıllık üretim ise 500-900 bin ton $\mathrm{y}^{-1}{ }^{-1}$ arasında değişmiştir. Balık üretiminde 1950'li y1llara kadara Sovyetler Birliği en büyük paya sahip iken, bu ülkeyi Türkiye ve Ukrayna izlemiştir. Türkiye'nin bu denizden elde ettiği üretim 1980'li yılların başlarından sonra hızla artarken, Rusya Federasyonu'nun üretimi hızla azalmıştır. Son yıllardaki üretim miktarları bakımından ülkeler Türkiye, Rusya Federasyonu, Ukrayna, Gürcistan, Bulgaristan ve Romanya şeklinde sıralanmaktadır.

Anahtar kelimeler: Karadeniz’e kıyısı olan ülkeler, Balıkçılık, Balıkçılık ekonomisi.

Maritime Jurisdiction Areas and Fisheries Activities of Riparian Countries in the Black Sea

\begin{abstract}
In this study, the fishing areas and efforts of Turkey, Georgia, Russia, Ukraine, Romania and Bulgaria have been compared and, fluctuations in the fish catch amounts of riparian countries were investigated since 1950. Fishing fleets and catch values were taken from "www.seaaroundus.org" and FAO fishing statistics. In addition, the official statistics of the countries and the results of the scientific researches were also used. By using the data, the roles of the riparian countries in the Black Sea fisheries was evaluated. While total catch obtained by the riparian countries from the Black Sea was between 400-500 thousand tons year ${ }^{-1}$ in the $1950 \mathrm{~s}$ and it was 1.3 million tons year ${ }^{-1}$ in the $1980 \mathrm{~s}$. However, at the end of the $1980 \mathrm{~s}$ it showed a rapid decline and fell to below 500 thousand tons in the early 1990s. Annual catch from the beginning of the 1990s to the recent years varied between 500 and 900 thousand tons. Until the late 1970s, the Soviet Union's share in this total catch was the highest and followed by Turkey and Ukraine. While the catch obtained by Turkish fishermen increased sharply in the early 1980s, it decreased sharply for Russian fishermen.
\end{abstract}

Keywords: Countries in the coast of Black Sea, Fishery, Fisheries economy.

\section{GíRiş}

Denizler, yazılı tarih öncesi çağlardan başlayarak insanlığa sundukları doğal kaynaklar ve kullanım olanakları ile bir ilgi ve etkinlik odağı oluşturmuşlardır. İlk yerleşim birimlerinin kurulduğu yerler özellikle göl, ırmak ve deniz kıyıları olmuştur. Suyun bu yapılanmada temel tercih olmasının başlıca nedenleri onun kullanımına duyulan ihtiyaç ve özellikle yaşamın sürdürülmesinde "vazgeçilmez" olmasıdır (Ergin, 2002). Günümüzde denizler, eskiden olduğu gibi sadece ülkeleri birbirinden ayıran doğal bir sınır değil, onları en kolay yoldan birbirine yaklaştıran su yolu, ekonomik ve kültürel kontak noktası ve önemli ekonomik bir kaynak durumundadır (Emiroğlu, 1987). 
Karadeniz 6 ülkeye kıyısı olan bir iç denizdir. İstanbul Boğazı aracıllı̆ı ile Marmara Denizi’yle, Kerç Boğazı'yla da Azak Denizi'yle bağlantılıdır. İstanbul Boğazı, 0,7-3,5 km genişliğinde, 39-100 m derinliğinde ve $31 \mathrm{~km}$ uzunluğunda dar, ince ve sığ bir kanaldır (Blacksea-comission, 2018). Karadeniz'in en derin bölgesi Türkiye'nin İnebolu açıkları $(2.206 \mathrm{~m})$ civarındadır. Ortalama derinliği ise 1.300 m'dir. Yüzölçümü, $36.875 \mathrm{~km}^{2}$ 'lik Azak Denizi ile birlikte $459.064 \mathrm{~km}^{2}$, su hacmi ise 537 bin $\mathrm{km}^{3}$ 'tür. Doğu-batı yönünde en uç noktalar arasındaki uzaklık $1.149 \mathrm{~km}$, kuzey-güney yönünde en fazla genişlik ise 611 km'dir. Karadeniz'in en dar kesiti olan, İnceburun (Sinop) ile Yalta kıyıları arasındaki mesafe 250 km'dir. En geniş yeri ise İstanbul Boğazı'nın Karadeniz girişi ile Dinyeper Irmağı ağız kısmı arasındadır (Doğanay, 1997).

Dinyeper, Dinyester, Tuna ve Don Avrupa'nın Karadeniz'e akan büyük nehirlerdir. Özellikle Tuna Nehri, tüm orta ve doğu Avrupa ile Balkanlar'ın endüstri ve evsel atık sularının boşaltıldığı bir yüzeysel su olup, doğal yaşam için ölümcül miktarda organik ve inorganik maddeyi Karadeniz'e taşımakta, kirli sular oradan da boğazlar yoluyla Marmara Denizi'ne taşınmaktadır. Karadeniz'in sadece ince bir üst su tabakasında (derinliği 150 m'ye kadar olan) canlı hayat söz konusudur. Daha derin katmanlarda ise yüzylllardan beri çürüyen organik maddelerin sebep olduğu hidrojen sülfür içeren su kütlesi mevcuttur. Bu nedenle 150 m'nin altındaki sularda sadece protozoalar, bakteriler ve bazı çok hücreli omurgasızlar yaşamaktadır. Ancak bu konudaki bilgiler de oldukça sınırlıdır. Bu iki farklı katman arasındaki dengenin bozulması ekosistemi ve insanlara telafisi zor zararlar verebilecek tehlikelere neden olabilir (Blacksea-comission, 2018).

Karadeniz'deki balık stokları bu denize kıyısı olan Türkiye, Gürcistan, Rusya Federasyonu, Ukrayna, Romanya ve Bulgaristan tarafından paylaşılmaktadır. $\mathrm{Bu}$ ülkelerden Romanya ve Bulgaristan AB üyesidir. Romanya ve Bulgaristan balıkçılık sahalarında yapılan çaça (Sprattus sprattus) ve kalkan (Scopthalmus maximus) balığ avcılığ için 2008 yılından itibaren kota uygulaması getirilmiştir. Son olarak, Akdeniz Genel Balıkçılık Komisyonu (GFCM)'nun 2018 y1lı için Ekim ayında almış olduğu kararı onamıştır. Söz konusu karara göre, Karadeniz'den Romanya ve Bulgaristan'ın 2018 yılında avlayabileceği toplam çaça miktarı 11.475 ton y11 ${ }^{-1}$, kalkan balığı miktarı ise 644 ton $\mathrm{y}_{1}{ }^{-1}$ dır. Özellikle son yıllarda aşırı avcılığın yaratmış olduğu tahribatı önlemek için GFCM ilk defa bazı yeni kararlar almıştır. Bu kararlara göre paydaş ülkeler, Karadeniz'deki kalkan avcılığı için çok yıllı bir yönetim planı üzerinde anlaşmışlardır. Anlaşma kısa vadede kalkan balığı için bir kota uygulanmasını öngörmekle birlikte, 2020 yılından itibaren ilave yönetim tedbirleri içeren tam teşekküllü bir yönetim planı haline gelecektir (European Commission, 2018).

Denizlerde doğal çevrenin ve canlılar arasındaki yaşamsal dengenin korunması, türlerin azalıp çoğalmalarına neden olacak genel ve yerel olumsuz faktörlerin ortadan kaldırılması ve engellenmesi gerekmektedir (Emiroğlu, 1987). Bu amaçla, başta su ürünleri stoklarında görülen azalmaya karş1 etkili önlemlerin alınması olmak üzere, kıyıdaş ülkelerin müşterek hareket etmelerini zorunlu kılmaktadır. Bu çalışmayla kıyısı olan ülkelerin 1950 yılından beri Karadeniz'den avladıkları balık türleri ve miktarları, av miktarlarındaki dalgalanmalar, kıyıdaş ülkelerin bu dalgalanmalara olan olası etkileri belirlenmeye çalışılmıştır.

\section{MATERYAL ve YÖNTEM}

$\mathrm{Bu}$ çalışmada, Karadeniz'e kıyısı olan ülkelerin öncelikle kıyı uzunluğu, kıta sahanlı̆̆ı, kıyı balıkçılık alanı ve münhasır ekonomik bölgesi gibi balıkçılık yetki alanlarının büyüklükleri tespit edilmiştir. Bu amaçla, Karadeniz ve Azak Denizi üzerine yapılmış araştırmalar taranmış, ülkelerin kıyı uzunlukları ve balıkçılık yetki alanları üzerine bildirilen verilerin doğruluğu haritalar üzerinden teyit edilmeye çalışılmıştır. Bunun yanı sıra kıyıdaş ülkelerin 1950 yılından günümüze kadar bu denizden avlamış oldukları su ürünlerinin miktarları Birleşmiş Milletler Gıda ve Tarım Örgütü (FAO) (2018) ve Sea Around Us (SAU) (2018) kayıtlarından çıkartılmış, Avrupa Komisyonu ve GFCM'in raporları ile bilimsel araştırmaların sonuçları incelenmiştir. Karadeniz'e kıyı olan ülkelerin balıkçılık yetki alanları ve elde etmiş oldukları su ürünleri av miktarlarından birim kıyı uzunluğu, münhasır ekonomik bölge, kıta sahanlığı ve kıyı balıkçılık alanı başına düşen yıllık av miktarları aşağıda verilen eşitlikler kullanılarak hesaplanmıştır. 
- Birim Kıyı Uzunluğu Başına Av Miktarı, $\mathrm{Y}_{(\mathrm{KU})}=\mathrm{Y} / \mathrm{KU}$

$\mathrm{Y}=$ Yıllık Av miktarı (Ton), KU=Kıyı Uzunluğu (km)

- Birim Münhasır Ekonomik Bölge Başına Av Miktarı, $\mathrm{Y}_{(\mathrm{MEB})}=\mathrm{Y} / \mathrm{MEB}$

MEB=Münhasır Ekonomik Bölge $\left(\mathrm{km}^{2}\right)$

- Birim Kıta Sahanlığg Başına Av Miktarı $\mathrm{Y}_{(\mathrm{KS})}=\mathrm{Y} / \mathrm{KS}$

$\mathrm{KS}=$ Kita Sahanlığ $1\left(\mathrm{~km}^{2}\right)$

- $\quad$ Birim Kıyı Balıkçılık Alanı Başına Av Miktarı $\mathrm{Y}_{(\mathrm{KBA})}=\mathrm{Y} / \mathrm{KBA}$

$\mathrm{KBA}=\mathrm{K} ı \mathrm{y}$ Balıkçılık Alanı $\left(\mathrm{km}^{2}\right)$

\section{BULGULAR ve TARTIŞMA}

Karadeniz; kuzeyi Ukrayna, kuzey-doğusu Rusya Federasyonu, doğusu Gürcistan, güneyi Türkiye, batısı Bulgaristan ve Romanya ile çevrili bir iç denizdir (Şekil 1).

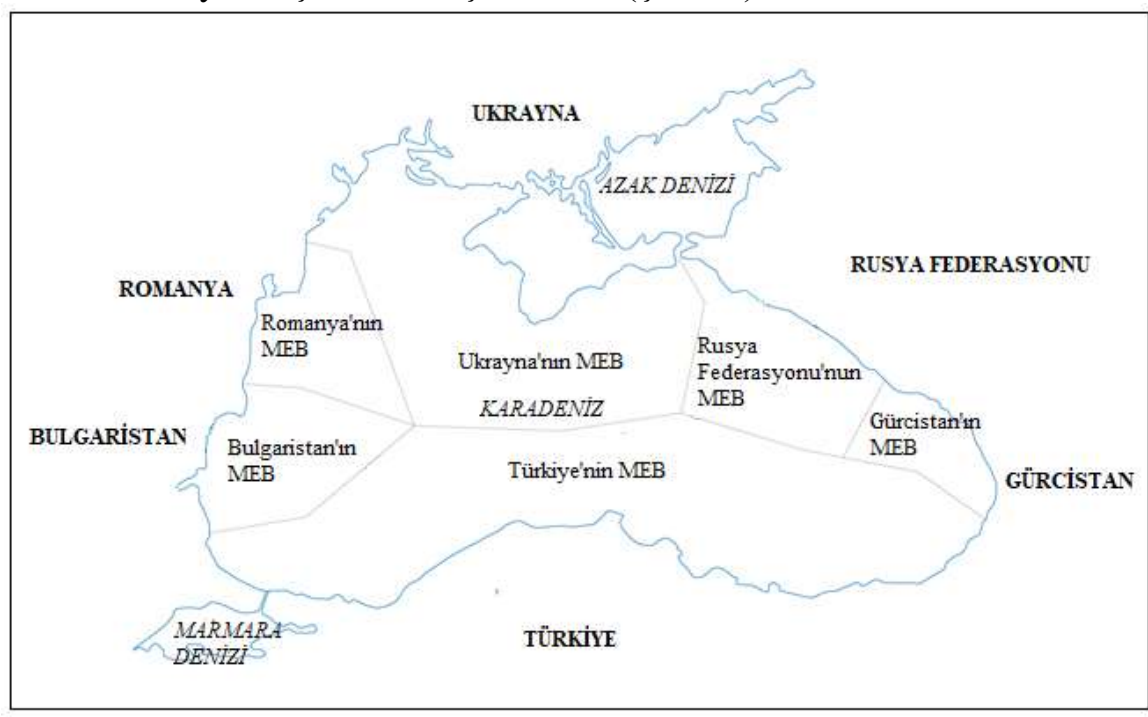

Şekil 1. Karadeniz ve kıyısı olan ülkeler.

Azak Denizi dahil Karadeniz'in toplam kıyı uzunluğu 4.869 km'dir. Bunun 3.456 km'sini Ukrayna $(1.756 \mathrm{~km}, \% 36,1)$ ve Türkiye $(1.700 \mathrm{~km}, \% 34,9)$ 'nin kıyıları oluşturmaktadır. Diğer ülkelerin Karadeniz'e olan kıyı uzunlukları ise Tablo 1'de görüldüğü gibi oldukça azdır.

Tablo 1. Karadeniz'e kıyısı olan ülkelerin kıyı uzunlukları, münhasır ekonomik bölgeleri, kıta sahanlıkları ve kıyı balıkçılık alanları.

\begin{tabular}{lllll}
\hline Ülke & $\begin{array}{l}\text { Kiyı uzunluğu } \\
(\mathrm{km})\end{array}$ & $\begin{array}{l}\text { MEB } \\
\left(\mathrm{km}^{2}\right)\end{array}$ & $\begin{array}{l}\text { Kita sahanlığı } \\
\left(\mathrm{km}^{2}\right)\end{array}$ & $\begin{array}{l}\text { Kiyı balıkçılık alanı } \\
\left(\mathrm{km}^{2}\right)\end{array}$ \\
\hline Türkiye & 1.700 & 172.484 & 18.899 & 18.899 \\
Gürcistan & 322 & 22.947 & 2.529 & 2.529 \\
Rusya Federasyonu & 421 & 67.351 & 19.828 & 18.906 \\
Ukrayna & 1.756 & 132.414 & 73.847 & 59.011 \\
Romanya & 256 & 29.756 & 23.283 & 10.790 \\
Bulgaristan & 414 & 35.132 & 11.902 & 11.243 \\
\hline Toplam & 4.869 & 460.084 & 150.288 & 121.378 \\
\hline \hline
\end{tabular}

Ülkelerin balıkçılık yapabilecekleri alanların sınırları, Birleşmiş Milletler Deniz Hukuku Sözleşmesinde (BMDHS) belirtilen kurallar çerçevesinde, kıyıdaş ülkelerle yapılan anlaşmalarla belirlenmiştir. Balıkçılık açısından bu sahaların en genişi ve en önemlisi Münhasır Ekonomik Bölge (MEB)'dir.

Birleşmiş Milletler Deniz Hukuku Sözleşmesi'nde MEB, kıyı devletine kara sularının ölçülmeye başlandığ 1 hattan itibaren 200 mil genişlikteki deniz alanında kalan su tabakası ile deniz yatağı ve onun toprak altında münhasır ekonomik haklar ve yetkiler tanıyan deniz alanı olarak tanımlanır 
(Karapınar, 2015). Söz konusu bölgede gerek deniz yatağı altında, gerekse içerisinde, su yüzeyi, toprak altı ve üstü, canlı ve cansız doğal kaynakların araştırılması, işletilmesi, korunması ve idaresine ilişkin kıyı devletine önemli ekonomik haklar ve yetkiler veren bir kavramdır (Kuran, 2009). Bu alan kıyı devletinin mutlak egemenliği altında bir alan olmayıp, kıyı devletine sadece doğal kaynaklar üzerinde münhasır yetkiler tanıyan bir deniz alanıdır. Dolayısıyla, kıyı ülkesinin balıkçılık faaliyetlerini sürdürebileceği sahanın sınırlarını belirleyen MEB'ye Karadeniz'de en fazla sahip olan ülke, Türkiye'dir. Toplam MEB'nin \%37,5'ine sahip olan Türkiye'yi \%28,8'lik MEB oranı ile Ukrayna izlemektedir. Şekil 1'de gösterilen harita incelendiğinde de görüleceği üzere diğer ülkelerin MEB'leri bu iki ülkeye göre oldukça küçüktür.

Kıta sahanlığı coğrafi olarak, kıyı devletinin denizin altında devam eden doğal uzantısıdır (Pazarcı, 1984). Hukuki anlamda ise kıta sahanlığı adı verilen bölge, kıyı devletinin karasularının ilerisinde ama kıyıya bitişik durumdaki deniz tabanı ve altındaki cansız varlıkların araştırılması ve işletilmesi konusunda münhasır hak sahibi olduğu deniz yetki alanıdır. Bu alan, kıyı çizgisinden 200 deniz mili uzaklığa ve hatta tabii kıta sahanlığ daha ileriye gidiyorsa deniz derinliğinin 2500 metreyi bulduğu izobar çizgisinin 150 deniz mili açığına kadar gidebilen ve üst sınırı her durumda 350 deniz mili olabilen bölgedir (Kuran, 2009). Chuenpagdee vd. (2006)'ye göre Kıyı Balıkç1lık Alanı terimi hangisi önce gelirse "kıyıdan $50 \mathrm{~km}$ açığa veya $200 \mathrm{~m}$ derinliğe" kadar olan kıyı şeridine verilen isimdir.

Kıta sahanlığı ve kıyı balıkçılık sahası bakımından ise en zengin ülke, Ukrayna'dır. Ukrayna'yı, kıta sahanlığı bakımından Romanya ve Rusya Federasyonu, kıyı balıkçılık sahası bakımından ise Rusya Federasyonu ve Türkiye izlemektedir. Ukrayna ve Rusya'nın gerek MEB'leri, gerekse kıta sahanlıkları ve kıyı balıkçııı sahalarının önemli bir kısmı Azak Denizi'nde bulunmaktadır. Özellikle Rusya Federasyonu'nun kıta sahanlığı ve kıyı balıkçılık sahası Karadeniz bölümünde oldukça sınırlı iken, Azak Denizi'nde oldukça geniştir. Diğer ülkelerden Romanya ve Bulgaristan ise hemen hemen eşit büyüklükte kıyı balıkçılık sahasına sahiptir. Ancak Romanya'nın sahip olduğu kıta sahanlığı Bulgaristan'a göre yaklaşık iki kat daha fazladır. Bulgaristan'ın MEB'si $\left(35.132 \mathrm{~km}^{2}\right)$ çok geniş değilse de kıta sahanlığı $\left(11.902 \mathrm{~km}^{2}\right)$ ve kıyı balıkçılık alanı $\left(11.243 \mathrm{~km}^{2}\right)$ oransal olarak oldukça fazladır. Gürcistan ise en az MEB, kıta sahanlı̆̆ 1 ve kıyı balıkçılık sahasına sahip olan ülkedir. Bu ülkenin özellikle kıta sahanlığı ve kıyı balıkçılık sahası oldukça sınırlıdır. Bu durum, Türkiye kıyılarında olduğu gibi dar bir kıta sahanlığına sahip olmasından ileri gelmektedir.

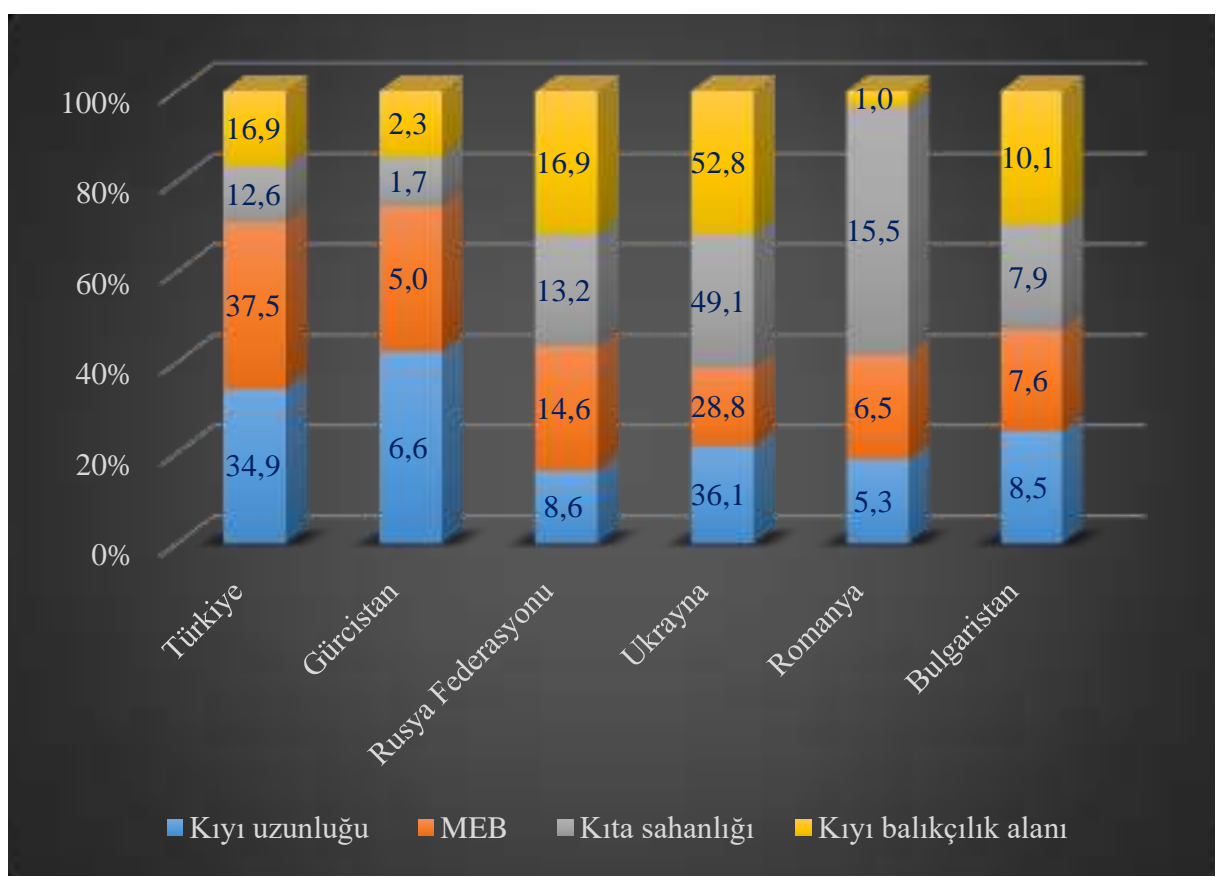

Şekil 2. Ülkelerin Karadeniz'e olan kıyı uzunlukları ile toplam MEB, kıta sahanlığı ve kıyı balıkçılık sahası içerisindeki payları. 


\section{Ülkelerin su ürünleri avcılığı}

Karadeniz'e kıyısı olan ülkeler, Karadeniz'den avladıkları su ürünleri miktarı bakımından karşılaştırıldığında, 1950 yılından 1970'li yılların sonlarına kadar Türkiye ile Rusya Federasyonu (Eski Sovyetler Birliği)'nun benzer miktarlarda su ürünleri avladıkları anlaşılmaktadır. Ancak, Şekil 3'de görüldüğü gibi 1970'li yılların sonlarından itibaren Türkiye'nin Karadeniz'den avladığı su ürünlerinin miktarı hızla artar iken, Rusya Federasyonu tarafından avlanan su ürünlerinin miktarı 1980’li yılların sonlarından itibaren önemli oranda azalmıştır.

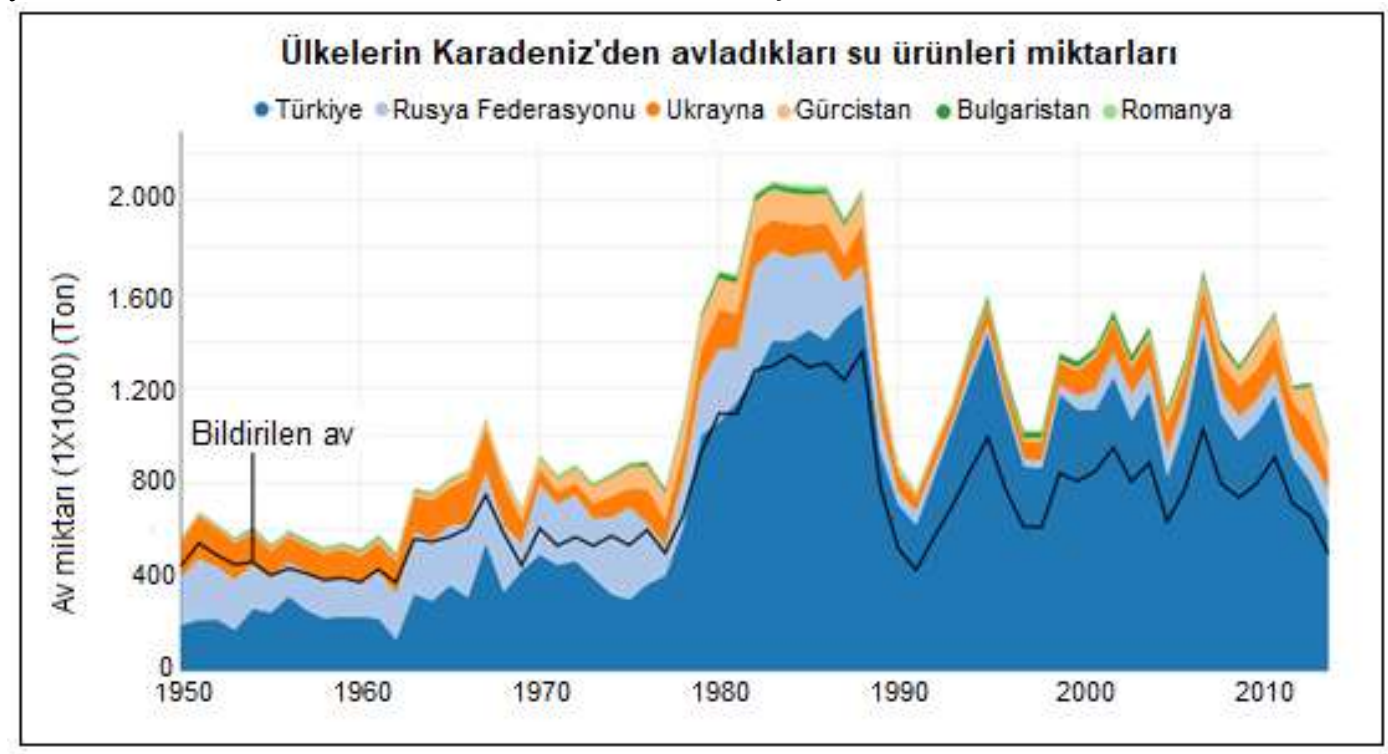

Şekil 3. Karadeniz'den, 1950 yılından 2014 yılına kadar avlanan su ürünlerinin, kıyısı olan ülkelere göre dağılımı.

SAU (2008) istatistiklerinden, 1970'li y1llardan itibaren Rusya Federasyonu'nun su ürünleri avcılığı için Karadeniz yerine Uzak Doğu'ya ve Barent Denizi'ne yöneldiği anlaşılmaktadır. Türkiye ise, 1990'l yılların ortalarına kadar sadece Akdeniz, Ege Denizi, Marmara Denizi ve Karadeniz'deki kendi yetki alanlarında avcılık yapmıştır. Ancak, 1990'lı yılların ortalarından itibaren yapılan anlaşmalarla Karadeniz'in Gürcistan sularında da avcılık yapmaya başlamıştır. Bunun yanı sıra son yıllarda Moritanya kıyılarında da su ürünleri avcılığı yapmaktadır. Rusya Federasyonu ve Türkiye'yi izleyen ülke ise, Ukrayna'dır. Ukrayna'nın Karadeniz'den avladığı su ürünlerinin miktarı 1950'li ve 1960'l y yllarda 40-60 bin ton arasında değişirken, 1970'li yılların başından itibaren artmaya başlamış ve 1980'li yıllarda 120-170 bin ton aralığına ulaşmıştır. 1990'l y1lların başlarında ise 60 bin tona kadar düşmüştür. 2000'li yıllara gelindiğinde ise tekrar 100 bin tonun üzerine çıkmış, o yıllardan itibaren bu ülkenin Karadeniz'den avladığı su ürünlerinin miktarı 100-120 bin ton aralığında seyretmektedir. Ukrayna'lı balıkçıların, Karadeniz'den daha çok 1960'lı yılların ortalarından 1990'lı yılların başlarına kadar Moritanya ve Fas, daha sonraki dönemlerde ise Moritanya, Yeni Zelanda ve Gine sularında avcılık yaptıkları anlaşılmaktadır (SAU, 2018). Karadeniz'in batı kıyısında yer alan Romanya ise verimli kıyı balıkçılık alanlarına sahip olmasına rağmen Karadeniz'den çok az su ürünleri avlayan bir ülkedir. Bu ülkenin Karadeniz'den avladığı yıllık su ürünleri 1950 yılından 2000'li yılların ortalarına kadar 5-18 bin ton arasında değişmiştir. Oysaki ülkenin 1980'li ve 1990'lı yıllarda rapor edilen su ürünleri av miktarı 150-200 bin ton, düzeltilmiş su ürünleri av miktarı ise 500550 bin tona kadar çıkmıştır. SAU (2018) istatistiklerinden bu üretimin çok az bir kısmının Karadeniz'den elde edildiği, çok büyük bölümünün Moritanya ve Namibya sularından avlandığı anlaşı1mıştır. Bulgaristan ise 1950 yılından 1960'lı yılların ortalarına kadar Karadeniz'den çok az su ürünleri avlayan bir ülkedir. Bu ülke balıkçılarının da 1970'li ve 1980'li yıllarda daha çok Namibya ve Fas sularından avcılık yaptıkları belirlenmiştir. Ancak, 1990'lı yılların ilk yarısından itibaren Bulgaristan'ın su ürünleri üretiminin tamamını Karadeniz'den elde edilen av oluşturmuştur (SAU, 2018).

Azak Denizi, Kerç Boğazıyla Karadeniz'e bağlanır ve sadece Rusya Federasyonu ile Ukrayna'nın bu denize kıyısı bulunmaktadır. FAO (2018)'nun balıkçılık istatistiklerine göre 2010-2015 yılları 
arasında Karadeniz kısmından avlanan su ürünlerinin \%75,3'nü Türkiye avlamıştır. Türkiye'yi, Rusya Federasyonu $(\% 8,5)$ ve Ukrayna $(\% 8,2)$ izlemiştir (Tablo 2). Azak kısmından avlanan ortalama 401,60 ton $\mathrm{y}_{1} 1^{-1}$ su ürünlerinin ise \% 68,4'ü Ukrayna tarafından avlanırken, \%31,6's1 Rusya Federasyonu tarafından avlanmıştır. Karadeniz'in genelinden avlanan su ürünlerinin ise \% 69,9'u Türkiye tarafından avlanmış, bu ülkeyi \%14,1'lik bir oran ile Ukrayna, \%10,7'lik oran ile de Rusya Federasyonu izlemiştir.

Tablo 2. Karadeniz ve Azak Denizi’nden 2010-2015 y1lları arasında avlanan su ürünlerinin ülkelere göre dağılımı (Ton) (FAO, 2018).

\begin{tabular}{lllllll}
\hline Ülkeler & Karadeniz & $\%$ & Azak & $\%$ & Toplam & $\%$ \\
\hline Türkiye & 279.220 & 75,3 & & & 279.220 & 67,9 \\
Gürcistan & 19.202 & 5,2 & & & 19.202 & 4,7 \\
Rusya & 31.430 & 8,5 & 12.682 & 31,6 & 44.118 & 10,7 \\
Federasyonu & 30.439 & 8,2 & 27.478 & 68,4 & 57.917 & 14,1 \\
Ukrayna & 1.706 & 0,4 & & & 1.706 & 0,4 \\
Romanya & 8.778 & 2,4 & & & 8.778 & 2,1 \\
Bulgaristan & 410.941 & 100 & 40.160 & 100 & 410.941 & 100 \\
\hline Toplam & & & & & & \\
\hline \hline
\end{tabular}

\section{Birim balıkçılık sahasından elde edilen av}

Birim kıyı uzunluğundan elde edilen su ürünleri avı bakımından, Karadeniz'den en fazla su ürünleri avlayan ülke Türkiye'dir. Bu ülkeyi sırasıyla Rusya Federasyonu, Gürcistan, Ukrayna ve Bulgaristan izlemiştir. Romanya'nın avladığ 1 su ürünlerinin miktarı ise diğer ülkelere oranla oldukça düşüktür. Birim MEB bakımından da en fazla su ürünleri avlayan ülkenin Türkiye olduğu, sırasıyla Gürcistan, Rusya Federasyonu ve Ukrayna'nın bu ülkeyi izlediği anlaşılmaktadır. Türkiye'nin birim kıta sahanlığı ve kıyı balıkçılık alanından elde ettiği su ürünlerinin miktarı da, Karadeniz'e kıyısı bulunan diğer ülkelere göre oldukça fazladır. Bu durum, Türkiye kıyılarındaki kıta sahanlığı ve dolayısıyla kıyı balıkçılık sahalarının oldukça dar bir şerit şeklinde kıyıya paralel olarak uzanmasından ileri gelmektedir. Özellikle dip balıkları bu kıyısal alanlardan avlanabilmektedir. Bu ülkeyi, gerek birim kıta sahanlığı gerekse birim kıyı balıkçılık sahasından elde edilen av bakımından sırasıyla Gürcistan ve Rusya Federasyonu izlemektedir (Tablo 3).

Tablo 3. Ülkelerin, 2010-2014 yılları arasında Karadeniz'den elde etmiş oldukları ortalama $\mathrm{Y}_{(\mathrm{KU})}$ (Birim kıyı uzunluğu başına elde edilen av), $\mathrm{Y}_{(\mathrm{MEB})}$ (Birim münhasır ekonomik bölge başına elde edilen av), $\mathrm{Y}_{(\mathrm{KS})}$ (Birim kıta sahanlığı başına elde edilen av) ve $\mathrm{Y}_{(\mathrm{KBA})}$ (Birim kıyı balıkçılık alanı başına elde edilen av) değerleri (Ton).

\begin{tabular}{llllll}
\hline \hline Ülke & Av & $\mathrm{Y}_{(\mathrm{KU})}$ & $\mathrm{Y}_{(\mathrm{MEB})}$ & $\mathrm{Y}_{(\mathrm{KS})}$ & $\mathrm{Y}_{(\mathrm{KBA})}$ \\
\hline Türkiye & 279.220 & 164,2 & 1,6 & 14,8 & 14,8 \\
Gürcistan & 19.202 & 59,6 & 0,8 & 7,6 & 7,6 \\
Rusya Federasyonu & 44.118 & 104,8 & 0,7 & 2,2 & 2,3 \\
Ukrayna & 57.917 & 33,0 & 0,4 & 0,8 & 1,0 \\
Romanya & 1.706 & 6,7 & 0,1 & 0,1 & 1,6 \\
Bulgaristan & 8.778 & 21,2 & 0,2 & 0,7 & 0,8 \\
\hline Toplam & 410.941 & 84,4 & 0,9 & 2,7 & 3,4 \\
\hline \hline
\end{tabular}




\section{Avın tür kompozisyonu}

Türkiye'nin Karadeniz'den avladığı balığın çok önemli bir kısmını 1950 yılından itibaren sürekli hamsi oluşturmuştur. Türk balıkçılar tarafindan 1950'li ve 1960'lı yıllarda hamsi ile birlikte palamut (Sarda sarda) en fazla avlanan balık türleri iken, 1980'li yıllarda palamut'un yerini istavrit (Trachurus spp.) almıştır. 2000'li yılların sonlarına gelindiğinde ise Türk balıkçıların hamsiden sonra Karadeniz'den en çok avladıkları ikinci balık türünün çaça olduğu anlaşılmaktadır (Şekil 4). Gürcistan'ın ise Karadeniz'den avladığı balık miktarı 1950'li yıllarda yok denecek kadar az iken, 1960'lı yılların başından itibaren özellikle hamsi (Engraulis encrasicolus) avcılığı artmaya başlamış ve 1980'li yıllarda 100 bin ton yı1 $^{-1}$ a kadar ulaşmıştır. Bu türün avı, 1980'li yılların sonlarında hızla düşmüş ise de 1990'lı yılların ortalarından itibaren tekrar yükselmeye başlamıştır. SAU (2018) verilerine göre Gürcistan'ın son yıllarda Karadeniz'den avladığ 1 hamsi miktarı 40-50 bin ton yl $^{1-1}$ 'dır. Rusya Federasyonu'nun ise 1950 yılından itibaren bilhassa 1990 yllına kadar Karadeniz'den en fazla avladığ 1 balık türü kilka (Clupeonella cultriventris) olmuştur. Bu balık türü sadece Azak Denizi kısmında dağılım göstermektedir. İkinci sırada ise hamsi gelmektedir. Hamsiyi de, 1950 ve 1960'lı yıllarda kayabalığı türleri (Gobiidae) izlerken, 2000'li yıllardan itibaren çaça izlemeye başlamıştır.

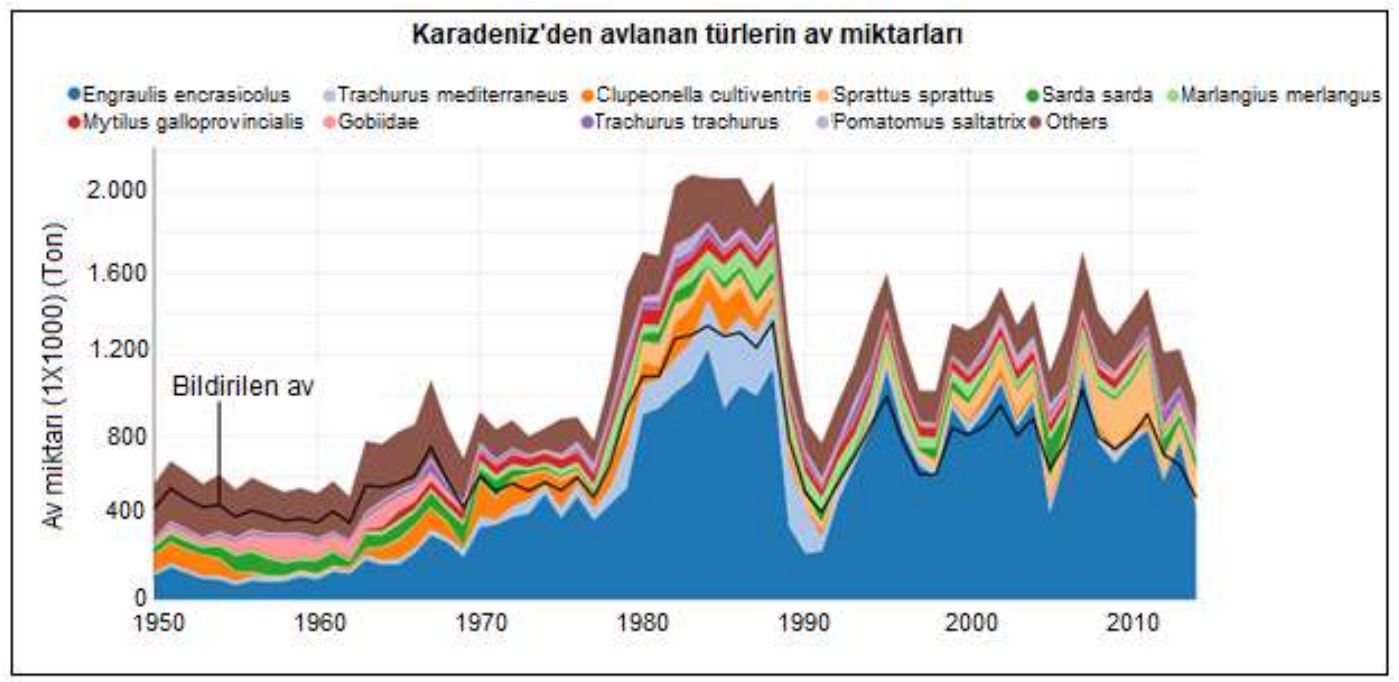

Şekil 4. Karadeniz'den, 1950 yılından itibaren avlanan su ürünlerinin türlere göre dağılımları (SAU, 2018).

Ukrayna tarafından 1950 yılından 1990 yılına kadar en çok hamsi avlanmıştır. 1950 ve 1960'lı yıllarda hamsinin yanı sıra kilka ve kayabalığı türlerinin de önemli miktarlarda avcılığının yapıldığı anlaşılmaktadır. 1970'li yılların ortaları ile 1990'lı yılların başları arasında ise en çok avlanan balık türü çaça olmuştur. Bu tür, 1990 y1lından itibaren hamsiden daha fazla miktarda avlanmaya başlanmıştır. 2000'li yılların başlarından itibaren Ukraynalı balıkçıların en fazla avladığı su ürünleri çaça ve hamsiden sonra sirasıla kilka, kayabalıkları, midye (Mytilus galloprovincialis), istavrit ve mezgittir. SAU (2018) verilerinden Ukraynalı balıkçıların, Moritanya, Fas, Yeni Zelanda ve Gana gibi ülkelerin sularında da su ürünleri avcılığı yaptıkları anlaşılmaktadır.

Karadeniz'in kuzey bölgeleri, palamut ve lüfer (Pomatomus saltatrix) gibi pelajik türler ile kalkan, küçük pisi balığı (Arnoglossus kesleri), pisi balığı (Platichthys flesus luscus) ve kum dil balığı (Solea lascaris nasus) gibi dip balıklarının en önemli üreme sahasıdır. Kuzey Karadeniz, Karadeniz hamsi stoku için ana üreme sahası, Karadeniz ve Azak hamsi stokları için de kışlama alanıdır (Chazchin, 1995; Svetovidov, 1964). Karadeniz'in kuzey-batısında avlanan Romanyalı balıkçılar, Karadeniz'den 1950 yılından 1970 yılına kadar en fazla hamsi, kilka, palamut ve kayabalığı avlamıştır. Daha sonraki yıllarda toplam av içerisinde hamsinin payı önemli oranda artmıştır. Özellikle 2000'li yılların sonlarından itibaren çaça avcılığ 1 önemli bir yer tutmaya başlamıştır. Bu dönem içerisinde Romanya'nın avladığı balığın daha çok çaça, hamsi, palamut ve istavrit’ten oluştuğu anlaşılmaktadır.

Karadeniz'in batı kıyısında yer alan Bulgaristan balıkçıları ise Karadeniz'den en çok pelajik türlerden çaça, istavrit, kefal, palamut ve lüfer; demersal türlerden ise barbunya (Mullus barbatus), köpek balığı (Squalus acanthias), vatoz (Raja clavata), kalkan ve kayabalığı avlamıştır. Ayrıca, deniz 
salyangozu (Rapana venosa) da avcılığı yapılan bir başka su ürünüdür (Sava, 2018). Bu ülkenin de Karadeniz'den avladığı su ürünlerinin miktarı oldukça düşük olup, 1950 yılından günümüze kadar 530 bin ton arasında değişmiştir. Avın önemli bir kısmını 1950'li ve 1960'lı yıllarda palamut oluştururken, 1980'li yıllardan itibaren bu türün yerini çaça almıştır.

SAU (2018)'a göre, Karadeniz'deki balık stoklarında özellikle 1960'lı yılların sonlarından itibaren ciddi gerileme başlamıştır. Dip balığı stoklarının 2014 yılı bulgularına göre; \%57,1'i çökmüş, \%19,6'sı da aşırı av baskısı altındadır. Karadeniz'den avlandığı bildirilen su ürünleri üretimi, 2000'li ve 2010'lu y1larda 600-700 bin ton civarında değişmektedir. Bildirilmeyen ya da eksik bildirilen miktarlar bakımından yapılan düzeltmeler sonras1 ise su ürünleri üretiminin 1,2-1,3 milyon ton civarına yaklaştığı anlaşılmaktadır. FAO (2016)'ya göre Akdeniz ve Karadeniz'deki balık stoklarının yaklaşı \%85'i biyolojik olarak sürdürülemez düzeylerde sömürülmektedir. Bu olumsuz gelişmemin önüne geçilebilmesi için Avrupa Komisyonu ve GFCM, Karadeniz'deki balıkçılık yönetimi için bölgesel bir yaklaşım geliştirme çabası içerisindedir. $\mathrm{Bu}$ amaçla, GFCM (2015) tarafindan Karadeniz'deki kalkan balıkçılığında yasa dışı, bildirilmemiş ve düzenlenmemiş balıkçılığın önlenmesi, engellenmesi ve ortadan kaldırılması için bazı önlemler alınmıştır. Ancak, AB sularındaki düzenlenmiş stokların miktarı, Karadeniz'deki toplam av miktarı içerisinde çok düşük bir yüzdeyi temsil etmektedir (STECF, 2015; FAO, 2016). Örneğin, 2012-2014 yılları arasında Karadeniz'den elde edilen çaça balığının sadece \%4-14'ü, kalkanın ise \%4,6-7'si AB sularından avlanmıştır (Raykov ve Düzgüneş, 2017). Dolayısıyla Karadeniz'in belirli bir kesiminde değil tamamında çöken ya da aşırı avcılık baskısı altındaki stoklar için benzer tedbirlerin alınması artık kaçınılmaz olmuştur.

Sonuç olarak, Karadeniz'deki balık stoklarında görülen aşırı sömürülmeyi durdurabilmek ve tekrar artış sağlayabilmek için hazırlanacak balıkçılık yönetimi uygulamalarında mutlaka av gücünün sınırlandırılması, endüstriyel balıkçılık için uygulanmakta olan desteklerin kaldırılması ve mevcut balıkçı1ık alanlarının büyük bir kısmının bazı avcılık yöntemlerine kapatılması yer almalıdır.

\section{KAYNAKLAR}

Blacksea-comission, (2018). (Blacksea-comission.org) (Erişim tarihi 6/04/2018). http://www.blackseacommission.org/

Chazchin, A.K. (1995). Abundance, distribution and migrations of anchovy stocks in the Black Sea. Turkish J. Zool., 19, 173-180.

Chuenpagdee, R., Liguori, L., Palomares, M. D., \& Pauly, D. (2006). Bottom-up, global estimates of small-scale marine fisheries catches. Fisheries Centre Research Reports 14(8), University of British Columbia, Vancouver. $112 \mathrm{pp}$.

Doğanay, H. (1997). Türkiye Beşeri Coğrafyası. MEB Yay. No: 2982, Bilim ve Kültür Eserleri Dizisi No: 877, Eğitim Dizisi No: 10, İstanbul, s. 130

European Commission, (2018). (Erişim tarihi 5/04/2018) https://ec.europa.eu/fisheries/cfp/international

Emiroğlu, M. (1987). Türkiye'nin Su Ürünleri Üretimi. Ankara Üniversitesi Dil ve Tarih-Coğrafya Fakültesi Dergisi, 31 (1-2), 77-146.

Ergin, A. (2002). Kıyı Mühendisliği. Kıyı ve Liman Mühendisliği, TMH - Türkiye Mühendislik Haberleri, 420421-422, 60-64.

FAO, (2016). Food and Agriculture Organization of the United Nations, The State of Mediterranean and Black Sea Fisheries. General Fisheries Commission for the Mediterranean. Rome.

FAO, (2018). Food and Agriculture Organization of the United Nations, Fisheries and Aquaculture Department. (Erişim tarihi 8/04/208). http://www.fao.org/fishery/en

GFCM, (2015). Report on the management of anchovy fisheries in the Black Sea (WKMEASURES - BS). Trabzon.

Karapınar, N. (2015). Birleşmiş Milletler Deniz Hukuku Sözleşmesi ve deniz alanlarına ilişkin bazı kavramlar. Doğal Kay. ve Eko. Bült., 20, 3-21.

Kuran, S. (2009). Uluslararası deniz hukuku, 3. Bask1. İstanbul.

Pazarcı, H. (1984). Kita Sahanlığı Kavramı ve Ege Denizi Kıta Sahanlığı Sorunu. Prof. Aziz Köklü’nün Anısına Armağan, A.Ü. SBF Yayınları, Ankara.

Raykov, V.S., \& Düzgüeş, E. (2017). Fisheries Management in the Black Sea-Pros and Cons. Front. Mar. Sci., 4, 227. doi: 10.3389/fmars.2017.00227

SAU, (2018). (Sea Around Us) (Erişim tarihi 5/04/2018). http://www.seaaroundus.org/data/\#/eez/794?chart=catch-chart\&dimension= commercialgroup \&measure $=$ tonnage $\&$ limit $=10$ 
Sava, D. (2018). Macrophytobenthos from the Romanian Black Sea coast-An overview of the studies and actual state. Chapter 6. In: C.W. Finkl, C. Makowski (eds.), Diversity in Coastal Marine Sciences, Coastal Research Library, 23, 369-382.

STECF, (2015). Scientific, Technical and Economic Committee for Fisheries (STECF) - Black Sea assessments (STECF-15-16). Luxembourg: Publications Office of the European Union, 284.

Svetovidov, A.N. (1964). Fishes of the Black Sea. Moscow: Nauka, 550 pp. 